Revista de

Contabilidade e

Organizações

www.rco.usp.br
DOI: http://dx.doi.org/10.11606/issn.1982-6486.rco.2020.168945

Journal of

Accounting and

Organizations

\title{
Níveis diferenciados de governança corporativa e a probabilidade de violação dos covenants financeiros
}

\author{
Differentiated levels of corporate governance and the probability of violating financial covenants
}

\author{
Willams da Conceição de Oliveira ${ }^{\mathrm{a}}$, Danilo Soares Monte-Mor ${ }^{\mathrm{b}}$
}

${ }^{a}$ Universidade Estadual de Alagoas

${ }^{b}$ Fucape Business School

\section{Palavras-chave}

Cláusulas restritivas financeiras.

Contratos de dívida.

Governança corporativa.

Níveis diferenciados.

Violação dos covenants.
Keywords

Financial covenants.

Debt contracts.

Corporate governance.

Differentiated levels.

Violating covenants.
Informações do artigo

Recebido: 21 de abril de 2020

Aprovado: 13 de outubro de 2020

Publicado: 28 de outubro de 2020

\section{Resumo}

A governança corporativa e os covenants financeiros exercem papéis complementares no monitoramento das companhias, na medida em que reduzem os conflitos de interesse entre as partes envolvidas durante a confecção de contratos de dívida. Esta pesquisa amplia esta discussão ao analisar se as companhias brasileiras de capital aberto listadas nos níveis diferenciados de governança corporativa da $\mathrm{B}^{3}$ apresentam menor probabilidade de violarem os covenants financeiros em uma análise ex-post à firmação dos contratos. A amostra abrangeu firmas brasileiras não financeiras de capital aberto no período de 2010 a 2018 , totalizando 1.310 observações em painel desbalanceado para 206 empresas. Os dados foram obtidos junto ao Economatica, site da $\mathrm{B}^{3}$ e construção de base própria a partir de informações de covenants constantes nas notas explicativas das respectivas firmas. Para apuração e análise dos resultados, foi realizado teste de média T Student e análise de regressão logística com efeito fixo de ano. Os resultados apresentam evidências de que as companhias listadas nos níveis diferenciados de governança corporativa da $\mathrm{B}^{3}$ apresentam menor probabilidade de violarem os covenants financeiros do que as demais companhias não listadas nos respectivos níveis. Tal evidência sugere que os níveis da $\mathrm{B}^{3}$ podem ser usados como proxy de governança em contextos contratuais em que existem conflitos de interesses entre as partes envolvidas.

\begin{abstract}
Corporate governance and financial covenants play complementary roles in monitoring companies as they reduce conflicts of interest between the parties involved when making debt contracts. This study expands this discussion by analyzing whether publicly traded Brazilian companies listed in B3's differentiated levels of corporate governance are less likely to violate financial covenants in an ex-post analysis of contract signing. The sample includes publicly traded non-financial Brazilian firms from 2010 to 2018, totaling 1,310 unbalanced panel observations for 206 companies. The data was obtained from Economatica, $B^{3 \prime} s$ website and a hand collected database consisting of covenant information from the explanatory notes of the respective firms. Student's mean t-test and a logistic regression analysis with year fixed effects were performed to calculate and analyze the results, which present evidence that companies listed on B3's differentiated levels of corporate governance are less likely to violate financial covenants than other unlisted companies. This evidence suggests that $B^{3}$ levels can be used as a proxy for governance in contractual contexts where there are conflicts of interest between the parties involved.
\end{abstract}

\section{Implicações Práticas}

As evidências suportam a possibilidade de uso dos níveis da B3 como proxy para governança em contextos em que existem conflitos de interesses entre as partes envolvidas. Na prática, tais níveis podem ser utilizados como subsídio adicional por credores na avaliação dos riscos contratuais e como fator que suporta e justifica a necessidade de inclusão de covenants financeiros nos contratos de dívida.

Copyright (C) 2020 FEA-RP/USP. Todos os direitos reservados.

Autor correspondente: Tel. (82) 3271-5276

E-mail: willams.oliveira@uneal.edu.br (W.da C. de Oliveira); danilo@fucape.br (D. S. Monte-Mor)

Universidade Estadual de Alagoas - Campus São Miguel dos Campos. Praça Nossa Senhora dos Prazeres, s./n. - Bairro de Fátima, São Miguel dos Campos/AL 57240-000, Brasil. 


\section{INTRODUÇÃO}

Covenants são cláusulas inseridas nos contratos de dívida que visam proteger os interesses dos credores, limitando o papel discricionário dos gestores e mitigando os problemas de agência entre as partes envolvidas nos contratos (Emira \& Amel, 2015; Demerjian, 2017; Prilmeier, 2017). A inclusão de tais cláusulas depende das características das empresas tomadoras de crédito e do tipo de dívida (Inamura, 2009; Moir \& Sudarsanam, 2007; Ismail, 2014).

As companhias que não respeitam os covenants financeiros estão sujeitas à repactuação da dívida, elevação da taxa de juros do contrato, obrigatoriedade de concessão de novas garantias (Press \& Weintrop, 1991; Beneish \& Press, 1993; Borges, 1999; Silva, 2008; Prilmeier, 2017), além da possibilidade de reclassificação para o curto prazo do saldo da dívida com vencimento em longo prazo, conforme CPC 26 (R1) - Apresentação das Demonstrações Contábeis (2011).

De uma forma geral, empresas com maiores níveis de risco e com menos mecanismos de controle são mais propensas a conflitos de interesse, desempenhando a governança papel importante na redução do risco e do custo dos contratos (Caixe \& Krauter, 2014). Nesse caso, a governança corporativa juntamente com os covenants financeiros desempenham papeis importantes na redução dos problemas de agência associados à formação de contratos de dívidas (Bakar, Mather \& Tanewski, 2012). Dada a relação de complementaridade entre tais mecanismos, a literatura apresenta evidências de que empresas que adotam boas práticas de governança corporativa apresentam, além de menores custos de financiamento e maior capacidade de financiamento (Funchal \& Monte-Mor, 2016), cláusulas contratuais menos restritivas (Klock, Mansi \& Maxwell, 2005; Li, Qiu \& Wan, 2011; Xi, Tuna \& Vasvari, 2014).

Estre trabalho amplia as discussões da literatura ao analisar a relação entre a governança e cláusulas restritivas a partir de uma perspectiva ex-post à geração dos contratos. Isso porque resultados como os de Palhares, Carmo, Ferreira e Ribeiro (2019) e Konraht e Vicente (2019) investigaram o impacto da governança corporativa na inclusão de covenants financeiros durante a emissão de debêntures. Necessita-se, assim, investigarmos se a relação de complementaridade entre governança e covenants financeiros se mantém após a confecção do contrato, estando a governança, portanto, influenciando a gestão dos covenants financeiros com vistas à não violação de tais cláusulas. Neste caso, esta pesquisa pretende responder a seguinte indagação: firmas com maiores níveis de governança apresentam menor probabilidade de violar os covenants financeiros? Especificamente, este trabalho objetiva analisar se as companhias brasileiras de capital aberto listadas nos níveis diferenciados de governança corporativa da $\mathrm{B}^{3}$ apresentam menor probabilidade de violar os covenants financeiros.

A governança corporativa é constituída por mecanismos que incentivam gestores a tomarem decisões com vistas à maximização do valor da firma (Denis \& McConnell, 2003; Ulum, Wafa, Karim \& Jamal, 2014). Em uma perspectiva de contratos de dívida, a governança é instituída por meio de ferramentas de gestão e requerimentos societários e de divulgação informacional, que aproximam os interesses de acionistas e credores, reduzindo os conflitos de interesses entre as partes envolvidas (Minadeo, 2018).

Dentre os diversos mecanismos de controle e monitoramento, a literatura brasileira tem utilizado os níveis diferenciados de governança corporativa da $\mathrm{B}^{3}$ como proxy para governança corporativa, na medida em que os níveis diferenciados (Nível 1, Nível 2 e Novo Mercado) consideram como requisitos obrigatórios pontos que envolvem o monitoramento exercido pelo conselho e mecanismos de liquidez e diluição do controle acionário $\left(B^{3}, 2020\right)$. Além disso, firmas listadas em tais níveis de governança apresentam maior grau de conservadorismo contábil, experimentam elevação nos seus valores de mercado e possuem redução nos respectivos riscos operacionais (Almeida, Scalzer \& Costa, 2008; Caixe \& Krauter, 2014).

Caso seja verificado que maiores níveis de governança da $\mathrm{B}^{3}$ reduzem a probabilidade de violação de cláusulas financeiras em contratos de dívida, as evidências suportariam a possibilidade de uso dos níveis da $\mathrm{B}^{3}$ como proxy para governança em contextos em que existem conflitos de interesses entre as partes envolvidas. Na prática, tais níveis poderiam ainda ser utilizados como subsídio adicional por credores na avaliação dos riscos contratuais e como fator que suporta e justifica a necessidade de inclusão de covenants financeiros mais restritivos nos contratos de dívida.

Para que fosse possível identificar se empresas com níveis diferenciados de governança corporativa da $\mathrm{B}^{3}$ possuem menor probabilidade de violação dos covenants financeiros, foram obtidas 1.310 observações de 206 companhias brasileiras de capital aberto, sendo que dados contábeis e de governança foram obtidos à base Economatica e site da $\mathrm{B}^{3}$. Informações sobre covenants financeiros foram obtidas por meio de coleta manual nas notas explicativas de cada uma das companhias da amostra. 
A partir da formação da base de dados, empresas com diferentes níveis de governança foram comparadas por meio de testes $t$ de diferença de médias. Regressões logísticas com efeito fixo de ano, também, foram utilizadas para a verificação da relação entre os níveis diferenciados de governança da $\mathrm{B}^{3}$ e a probabilidade de violação dos covenants financeiros.

De uma forma geral, os resultados obtidos evidenciam que companhias listadas nos níveis 1, 2 ou Novo Mercado apresentam menor probabilidade de violar os covenants financeiros de contratos de dívida em comparação com as demais companhias não listadas em tais níveis. Tal resultado, indica que os mecanismos de governança não só influenciam ex-ante a inclusão e o nível de restritividade dos covenants financeiros (Palhares et al., 2019; Konraht \& Vicente, 2019), mas também que tais mecanismos continuam a monitorar as ações dos gestores no que se refere à gestão dos indicadores associados aos covenants financeiros. Nesse caso, verifica-se que os níveis da $\mathrm{B}^{3}$ podem ser usados como proxy para governança em pesquisas cujos contextos envolvem a presença de conflitos de interesses entre partes envolvidas em contratos de dívidas.

As contribuições desse estudo se estendem ainda em uma perspectiva prática, na medida que suportam e justificam a inclusão de cláusulas financeiras mais restritas em contratos de dívidas de empresas não listadas nos níveis diferenciados de governança corporativa da $\mathrm{B}^{3}$. Tais níveis podem ser utilizados como subsídio adicional por credores na avaliação dos riscos contratuais e como fator que suporta e justifica a necessidade de inclusão de covenants financeiros nos contratos de dívida (Beiruth, Fávero, Murcia, Almeida \& Brugni, 2017).

\section{REFERENCIAL TEÓRICO}

\subsection{Covenants financeiros}

As instituições financeiras, além de exigirem as tradicionais garantias nas concessões de empréstimos, utilizam outros instrumentos de monitoramento como os covenants (Borges, 1999). Especificamente, covenants são cláusulas inseridas nos contratos de dívidas que visam proteger os interesses dos credores (Inamura, 2009). A inclusão de tais cláusulas está relacionada com o monitoramento requerido em função dos conflitos de agência associados às transações e à necessidade de informações adicionais acerca das empresas contratantes (Inamura, 2009; Demerjian, 2017; Prilmeier, 2017). Em outras palavras, a inclusão dos covenants em contratos de dívida visa transmitir informações privadas aos credores sobre as projeções financeiras das companhias, reduzindo assim, o nível de assimetria (Demiroglu \& James, 2010).

As cláusulas restritivas financeiras representam uma parte importante dos contratos de dívida e são em geral baseadas nas informações contábeis dos devedores, sendo geralmente expressas como índices contábeis que possuem faixas definidas previamente nos contratos (Demiroglu \& James, 2010). Tais cláusulas impõe restrições diretas às atividades financeiras e de investimento dos devedores, o que serve como mecanismo que limita as ações discricionárias dos gestores e protegem os investidores no que tange à continuidade operacional e capacidade de pagamento de longo prazo das empresas credoras (Chava, Fang, Kumar \& Prabhat, 2019). Como exemplos de cláusulas restritivas financeiras podemos citar os covenants de capital, os quais controlam os conflitos de agência impondo restrições à estrutura de capital; e os covenants de performance, que acompanham o desempenho financeiro e operacional das companhias (Christensen \& Nikolaev, 2012).

Outras cláusulas são também exploradas pela literatura como covenants financeiros. Nini, Smith e Sufi (2009), por exemplo, evidenciaram nos contratos de dívidas das empresas canadenses covenants que foram agrupadas em seis classes: endividamento no balanço, cobertura da dívida, endividamento no fluxo de caixa, liquidez, patrimônio líquido e covenants de EBITDA. Nas empresas americanas, Prilmeier (2017) destacou covenants financeiros relacionados ao endividamento do balanço, cobertura da dívida, capacidade de pagamento e EBITDA. No Brasil, Duarte e Galdi (2018) identificaram nos contratos de dívida covenants financeiros relacionados ao EBITDA, receita líquida, dívida líquida, cobertura da dívida, despesa financeira, liquidez corrente e restrição de investimentos, cláusulas estas relacionadas aos tipos de covenants financeiros utilizados no Canadá e EUA.

Independente do indicador utilizado, a violação dos covenants financeiros em geral possui implicações negativas às empresas, como o vencimento antecipado do empréstimo, elevação da taxa de juros do contrato na repactuação da dívida, concessão de novas garantias, penalidades que afetam o fluxo de caixa e até mesmo a continuidade operacional (Press \& Weintrop, 1991; Beneish \& Press, 1993; Borges, 1999; Silva, 2008; Prilmeier, 2017). No Brasil, segundo CPC 26 (R1), as companhias que violarem um acordo contratual (covenant) são obrigadas a reclassificar para o curto prazo o saldo da dívida relacionada ao acordo violado e divulgar o evento nas notas explicativas. Nesse sentido, gestores têm incentivos à tomarem decisões de forma a evitar que tais cláusulas sejam acionadas (Costa, Matte \& Monte-Mor, 2018). 
Como exemplo, verificam-se pesquisas que indicam que as empresas que apresentam melhor qualidade nos relatórios financeiros e maior responsabilidade social corporativa possuem menor quantidade de covenants financeiros nos contratos de dívida (Costello \& Moerman, 2011; Shi \& Sun, 2015). Outros resultados indicam que empresas que reconhecem mais perdas possuem mais covenants financeiros em contratos de dívida (Nikolaev, 2010), e que a proximidade de violar os covenants financeiros influencia os gestores a utilizarem escolhas contábeis para evitar a violação e consequentemente os prejuízos gerados (Iatridis \& Kadorinis, 2009; Silva, 2008; Franz, Hassabelanby \& Lobo, 2014; Beiruth et al., 2017; Duarte \& Galdi, 2018). Na próxima subseção explora-se o papel da governança como ator complementar aos covenants financeiros na redução dos conflitos de agência entre as partes envolvidas nos contratos de dívida.

\subsection{Governança corporativa e covenants financeiros}

O objetivo da governança corporativa é diminuir os problemas de agência nos setores privado e público (Miglani, Ahmed, \& Henry, 2015; Dawson, Denfrod, Williams, Preston \& Desouza, 2016), sendo utilizada para garantir o retorno dos investimentos dos acionistas (Shleifer \& Vishny, 1997). As companhias que implantam as boas práticas de governança corporativa transmitem mais segurança ao investidor, refletindo na valorização, na eficiência operacional e na redução dos custos de agência (Robicheaux, Fun \& Ligon, 2007; Silva, Santos \& Almeida, 2011; Gondrige, Clemente \& Espej, 2012; Sonza \& Kloeckner, 2014; Mapurunga, Ponte \& Oliveira, 2015; Baioco \& Almeida, 2017; Machado \& Gartner, 2018).

Além disso, a adoção das boas práticas de governança corporativa influencia na elevação e qualidade dos lucros, na redução do nível de gerenciamento de resultados, na redução do endividamento bancário e no custo de financiamento das dívidas, passando as companhias a utilizarem mais dívidas de curto prazo do que dívidas de longo prazo. Sendo a dívida de curto prazo, portanto, um disciplinador para os gestores na tomada de decisão (Silva et al., 2011; González \& García-Meca, 2014; Maranho \& Leal, 2018; Nisiyama \& Nakamura, 2018).

Palhares et al. (2019) identificaram que o tamanho do conselho administrativo e a concentração de propriedade são fatores fundamentais na quantidade de covenants financeiros a serem inseridos nos contratos de dívida. Identificaram ainda que a concentração de propriedade, o tamanho e a independência do conselho administrativo influenciam o nível de restrição do covenant financeiro "Dívida Financeira Líquida/EBITDA" inserido na emissão de debêntures (Palhares et al., 2019). Tais mecanismos de governança são destacados como fatores analisados ex-ante ao fechamento do contrato e se relacionam diretamente com as regras implementadas pela $\mathrm{B}^{3}$ referentes aos requisitos mínimos de entrada nos diferentes níveis de governança, conforme Figura 1.

Os níveis de governança da $\mathrm{B}^{3}$ compreendem o Tradicional, Bovespa Mais, Nível 1, Nível 2 e Novo Mercado e têm como objetivo melhorar as avaliações daquelas companhias que aderem voluntariamente aos respectivos níveis $\left(\mathrm{B}^{3}, 2020\right)$. Conforme Figura 1, empresas inseridas no Novo Mercado e no Nível 2 devem ter no mínimo 5 membros no conselho de administração, dos quais pelo menos $20 \%$ devem ser independentes com mandato unificado de até 2 anos. Insere-se à esse grupo as empresas listadas no Nível 1, as quais juntamente com empresas do Novo Mercado e Nível 2 possuem vedações com relação ao acúmulo de cargo no conselho, devendo a partir de 10/05/2011 o presidente do conselho e diretor presidente ou principal executivo ter carência mínima de 3 anos no cargo a partir da adesão.

Além de mecanismos de controle da composição do conselho, empresas listadas no Nível 1, Nível 2 e no Novo Mercado devem ainda possuir no mínimo $25 \%$ das ações em circulação (free float) e garantir esforços de dispersão acionária $\left(\mathrm{B}^{3}, 2020\right)$. Tais pontos se relacionam diretamente com os resultados de Palhares et al. (2019), os quais identificaram que o tamanho do conselho administrativo e a concentração de propriedade são fatores fundamentais na quantidade de covenants financeiros a serem inseridos nos contratos de dívida.

Nesse caso, os níveis diferenciados da $\mathrm{B}^{3}$ (Nível 1, Nível 2 e Novo Mercado), por considerarem como requisitos obrigatórios pontos que envolvem o monitoramento exercido pelo conselho e mecanismos de liquidez e diluição do controle acionário, têm possibilidade de limitar as ações discricionárias dos gestores, o que reduziria a probabilidade de covenants financeiros serem violados, o que deriva a hipótese dessa pesquisa:

$\mathbf{H}_{1}$ : As companhias brasileiras listadas nos níveis diferenciados de governança corporativa da $\mathrm{B}^{3}$ apresentam menor probabilidade de violarem os covenants financeiros estabelecidos nos contratos de dívida. 


\begin{tabular}{|c|c|c|c|c|c|}
\hline & NOVO MERCADO & NINEL 2 & NÍVEL 1 & BOVESPA MAIS & TRADICIONAL \\
\hline $\begin{array}{l}\text { Características das Açöes } \\
\text { Emitidas }\end{array}$ & $\begin{array}{l}\text { Permite a existência } \\
\text { somente de ações ON }\end{array}$ & $\begin{array}{l}\text { Permite a existência de } \\
\text { ações ON e PN (com } \\
\text { direitos adicionais) }\end{array}$ & $\begin{array}{l}\text { Permite a existência de } \\
\text { ações ON e PN (conforme } \\
\text { legislação) }\end{array}$ & $\begin{array}{c}\text { Somente ações ON podem } \\
\text { ser negociadas e emitidas, } \\
\text { mas é permitida a } \\
\text { existência de PN }\end{array}$ & $\begin{array}{l}\text { Permite a existência de } \\
\text { ações ON e PN (conforme } \\
\text { legislação) }\end{array}$ \\
\hline $\begin{array}{l}\text { Percentual Mínimo de } \\
\text { Ações em Circulação } \\
\text { (free float) }\end{array}$ & \multicolumn{3}{|c|}{ No mínimo $25 \%$ de free float } & $\begin{array}{c}25 \% \text { de free float até o } 7^{\circ} \\
\text { ano de listagem, ou } \\
\text { condições mínimas de } \\
\text { liquidez }\end{array}$ & Não há regra \\
\hline $\begin{array}{l}\text { Distribuiçöes públicas de } \\
\text { açőes }\end{array}$ & \multicolumn{3}{|c|}{ Esforços de disper são acionária } & \multicolumn{2}{|c|}{ Não há regra } \\
\hline $\begin{array}{l}\text { Vedação a dis posiçőes } \\
\text { estatutárias (a partir de } \\
\text { 10/05/2011) }\end{array}$ & \multicolumn{2}{|c|}{$\begin{array}{l}\text { Limitação de voto inferior a } 5 \% \text { do capital, quorum } \\
\text { qualificado e "cláusulas pétreas" }\end{array}$} & \multicolumn{3}{|c|}{ Não há regra } \\
\hline $\begin{array}{l}\text { Composição do Conselho } \\
\text { de Administração }\end{array}$ & \multicolumn{2}{|c|}{$\begin{array}{l}\text { Mínimo de } 5 \text { membros, dos quais pelo menos } 20 \% \\
\text { devem ser independentes com mandato unificado de } \\
\text { até } 2 \text { anos }\end{array}$} & \multicolumn{3}{|c|}{ Mínimo de 3 membros (conforme legislação) } \\
\hline $\begin{array}{l}\text { Vedação à acumulação de } \\
\text { cargos (a partir de } \\
\text { 10/05/2011) }\end{array}$ & \multicolumn{3}{|c|}{$\begin{array}{l}\text { Presidente do conselho e diretor presidente ou principal executivo pela mesma } \\
\text { pessoa (carência de } 3 \text { anos a partir da adesão) }\end{array}$} & \multicolumn{2}{|c|}{ Não há regra } \\
\hline $\begin{array}{l}\text { Obrigação do Conselho } \\
\text { de Administração (a partir } \\
\text { de 10/05/2011) }\end{array}$ & \multicolumn{2}{|c|}{$\begin{array}{l}\text { Manifestação sobre qualquer oferta pública de } \\
\text { aquisição de ações da companhia }\end{array}$} & \multicolumn{3}{|c|}{ Não há regra } \\
\hline $\begin{array}{l}\text { Demonstrações } \\
\text { Financeiras }\end{array}$ & \multicolumn{2}{|c|}{ Traduzidas para o inglês } & \multicolumn{3}{|c|}{ Conforme legislação } \\
\hline $\begin{array}{l}\text { Reunião pública anual e } \\
\text { calendário de eventos } \\
\text { corporativos }\end{array}$ & \multicolumn{3}{|c|}{ Obrigatório } & \multicolumn{2}{|c|}{ Facultativo } \\
\hline $\begin{array}{l}\text { Divulgação adicional de } \\
\text { informações (a partir de } \\
\text { 10/05/2011) }\end{array}$ & \multicolumn{3}{|c|}{ Poltica de negociação de valores mobiliários e código de conduta } & \multicolumn{2}{|c|}{ Não há regra } \\
\hline \multirow{2}{*}{ Concessão de Tag Along } & \multirow[b]{2}{*}{$100 \%$ para ações ON } & $100 \%$ para ações ON e PN & \multirow{2}{*}{$\begin{array}{l}80 \% \text { para ações ON } \\
\text { (conforme legislação) }\end{array}$} & \multirow[b]{2}{*}{$100 \%$ para ações ON } & \multirow{2}{*}{$\begin{array}{l}80 \% \text { para ações ON } \\
\text { (conforme legislação) }\end{array}$} \\
\hline & & $\begin{array}{c}100 \% \text { para ações ONe } \\
80 \% \text { para PN (até } \\
09 / 05 / 2011)\end{array}$ & & & \\
\hline $\begin{array}{l}\text { Oferta pública de } \\
\text { aquisição de açöes no } \\
\text { mínimo pelo valor } \\
\text { econômico }\end{array}$ & \multicolumn{2}{|c|}{$\begin{array}{l}\text { Obrigatoriedade em caso de fechamento de capital ou } \\
\text { saida do segmento }\end{array}$} & Conforme legislação & $\begin{array}{l}\text { Obrigatoriedade em caso } \\
\text { de fechamento de capital } \\
\text { ou saída do segmento }\end{array}$ & Conforme legislação \\
\hline $\begin{array}{l}\text { Adesão à C âmara de } \\
\text { Arbitragem do Mercado }\end{array}$ & \multicolumn{2}{|c|}{ Obrigatório } & Facultativo & Obrigatório & Facultativo \\
\hline
\end{tabular}

Figura 1. Critérios necessários para uma empresa ser listada nos diferentes níveis da B3

Fonte: Bússula do Investidor (2020)

A literatura ainda apresenta diversos benefícios oriundos da adesão aos níveis diferenciados da $\mathrm{B}^{3}$, dentre os quais incluem-se: aumento do valor de mercado das companhias (Rossoni \& Silva, 2013; Clemente, Antonelli, Scherer \& Mussi, 2014); aumento da precisão das previsões dos analistas (Dalmácio, Lopes, Sarlo Neto \& Rezende, 2011); aumento da imagem institucional das companhias (Nardi \& Nakao, 2008); maior retorno anormal em operações de fusão e aquisição (Silva, Kayo \& Nardi, 2016); menor custo de financiamento da dívida e cláusulas contratuais com menos restritivas (Klock et al., 2005; Li et al., 2011), dentre outros. Todos esses resultados corroboram com o papel exercido pela governança na redução dos problemas de agência associados à formação de contratos de dívidas (Bakar et al., 2012).

Dada a relação de complementaridade entre a governança e covenants financeiros na limitação das ações discricionárias do gestor e na mitigação de conflitos de agência, a proposição prevista na hipótese 1 amplia as discussões da literatura ao analisar a relação entre a governança e cláusulas restritivas a partir de uma perspectiva ex-post à geração dos contratos, exercendo a governança papel influenciador da gestão dos covenants financeiros com vistas à não violação de cláusulas financeiras em contratos de dívida. 


\section{METODOLOGIA}

\subsection{Coleta de dados e amostra}

Foi necessário desenvolver para variável explicada uma base própria por meio da coleta manual dos dados nas notas explicativas que foram baixadas no site da $\mathrm{B}^{3}$ e site das companhias que compõem a amostra, utilizando as palavras chaves "covenants", "cláusulas", "restritivas", "convênios" e "índices" para identificação dos covenants na nota explicativa dos contratos de dívida bancária, conforme estudo desenvolvido por Duarte e Galdi (2018).

Para realização do estudo foram consideradas as companhias brasileiras não financeiras de capital aberto listadas na B B $^{3}$ abrangendo o período pós-IFRS de 2010 a 2018. O período pós-IFRS foi selecionado na medida em que o IFRS alterou o padrão de inclusão de covenants financeiros nos contratos de dívida (Beiruth et al., 2017). A amostra final foi composta por 1.310 observações em painel desbalanceado para 206 empresas, conforme limpeza de dados apresentada na Tabela 1 .

Tabela 1. Processo de seleção amostral

\begin{tabular}{lc}
\hline \multicolumn{1}{c}{ Ação realizada } & N $^{\mathbf{0}}$ Obs. \\
\hline Total de observações baixadas do Economatica & 3.053 \\
Retirada as observações onde não foram localizadas as notas explicativas & $(533)$ \\
Retirada as observações em que as empresas não divulgaram voluntariamente se tinham ou não covenants & $(601)$ \\
financeiros & $(297)$ \\
Retirada as observações com patrimônio líquido negativo & $(271)$ \\
Retirada as observações em que as empresas não tinham covenants financeiros & $(21)$ \\
Retirada as empresas que não possuíam dívidas bancárias no respectivo ano da observação & $(20)$ \\
Retirada as observações sem dados do EBITDA & $\mathbf{1 . 3 1 0}$ \\
\hline Amostra final &
\end{tabular}

Fonte: elaborada pelos autores

Foram desconsideradas as observações em que as empresas não informaram nas notas explicativas se tinham ou não covenants financeiros, levando em consideração que as companhias brasileiras são obrigadas a divulgar essa informação quando ocorrer a violação do covenant financeiro conforme CPC 26 (R1). O Apêndice A apresenta, em detalhes por ano, o número de empresas que apresentam covenants e que violaram tais cláusulas, conforme informações constantes nas notas explicativas.

Para identificação dos níveis diferenciados de governança corporativa, foi considerada a classificação da $\mathrm{B}^{3}$ atualizada em 18 de junho de 2018 e utilizando a data de adesão no segmento para classificação das companhias nos respectivos níveis e anos, conforme Tabela 2.

Tabela 2. Quantidade de observações da amostra classificadas nos níveis de governança corporativa da B ${ }^{3}$

\begin{tabular}{clcccccccccc}
\hline Classificação & Níveis B $^{\mathbf{3}}$ & $\mathbf{2 0 1 0}$ & $\mathbf{2 0 1 1}$ & $\mathbf{2 0 1 2}$ & $\mathbf{2 0 1 3}$ & $\mathbf{2 0 1 4}$ & $\mathbf{2 0 1 5}$ & $\mathbf{2 0 1 6}$ & $\mathbf{2 0 1 7}$ & $\mathbf{2 0 1 8}$ & Total \\
\hline \multirow{2}{*}{ Não listadas } & Não listadas & 51 & 52 & 61 & 64 & 70 & 70 & 69 & 67 & 63 & 567 \\
e níveis não & Tradicional & 7 & 6 & 6 & 6 & 7 & 7 & 7 & 6 & 6 & 58 \\
diferenciados & Bovespa Mais & 0 & 0 & 1 & 1 & 1 & 1 & 1 & 1 & 1 & 7 \\
\hline \multirow{2}{*}{ Níveis } & Nível 1 & 12 & 12 & 14 & 15 & 15 & 14 & 15 & 15 & 15 & 127 \\
diferenciados & Nível 2 & 4 & 6 & 6 & 8 & 7 & 5 & 8 & 8 & 10 & 62 \\
& Novo Mercado & 40 & 48 & 53 & 56 & 57 & 57 & 54 & 62 & 62 & 489 \\
\hline \multicolumn{2}{c}{ Total de observações } & $\mathbf{1 1 4}$ & $\mathbf{1 2 4}$ & $\mathbf{1 4 1}$ & $\mathbf{1 5 0}$ & $\mathbf{1 5 7}$ & $\mathbf{1 5 4}$ & $\mathbf{1 5 4}$ & $\mathbf{1 5 9}$ & $\mathbf{1 5 7}$ & $\mathbf{1 3 1 0}$
\end{tabular}

Fonte: elaborada pelos autores 


\subsection{Design empírico}

Para testar a hipótese 1 de que as companhias listadas nos diferentes níveis de governança corporativa apresentam menor probabilidade de violar os covenants financeiros estabelecidos nos contratos de dívida, foi realizado inicialmente teste de média $\mathrm{T}$ Student para que fosse verificado se em média empresas listadas nos níveis diferenciados de governança da $\mathrm{B}^{3}$ (Nível 1, Nível 2 ou Novo Mercado) violam menos covenants financeiros que empresas não listadas em tais níveis. Em seguida, utilizou-se uma regressão logística com efeito fixo de ano (equação 1), a qual permite identificar se companhias listadas em níveis diferenciados de governança corporativa apresentam menor probabilidade de violarem os covenants financeiros. O efeito fixo de ano foi inserido para capturar choques que podem levar empresas a violarem cláusulas restritivas por questões de mercado que estão além de decisões gerenciais da firma. Conforme hipótese 1, espera-se que companhias listadas nos diferentes níveis de governança corporativa apresentam menor probabilidade de violar os covenants financeiros, ou seja, que o coeficiente $\beta_{1}$ apresente sinal negativo.

$$
\text { Probabilidade (Violação } \left.{ }_{i t}=1 / X\right)=1 /\left(1+e^{-z}\right. \text { ) }
$$

$\operatorname{com} Z=\beta_{0}+\beta_{1}$ Niveis diferenciados de Governança Corporativa $a_{i t}+\sum_{k} \beta_{k}$ Contoles $_{i t}{ }^{k}+\varepsilon_{i t}$,

e sendo as variáveis utilizadas descritas conforme a seguir:

$V_{\text {Violação }}$ : variável dummy igual a 1 se a empresa $i$ violou ao menos um covenant financeiro no período $t$, e 0 caso contrário;

Niveis diferenciados de Governança Corporativa $a_{i t}$ dummy que representa os níveis diferenciados de governança corporativa, assumindo valor 1 se a empresa $i$ pertence a um dos níveis diferenciados de governança corporativa (Nível 1, Nível 2 ou Novo Mercado), e igual a 0 caso contrário.

Para que fosse possível controlar as heterogeneidades existentes entre as empresas da amostra, o modelo da equação 1 considera ainda o tamanho, o nível de gerenciamento de resultados, a alavancagem, a taxa de crescimento da receita líquida e a rentabilidade das empresas, conforme descrito na subseção a seguir.

\subsection{Variáveis de controle}

A variável Tamanho é mensurada por meio do logaritmo natural do ativo total das companhias. Espera-se que as empresas maiores influenciem na inclusão de covenants financeiros menos restritivos e apresentem menor probabilidade de violar os covenants financeiros (Freudenberg, Imbierowicz, Saunders \& Steffen, 2011; Bakar et al., 2012; Dahrawy, Ghany \& Mohamed, 2015; Palhares et al., 2019).

O Gerenciamento de resultados é calculado pelo modelo de Dechow, Sloan \& Sweeney (1995) para mensuração do nível de accruals discricionários. Quando as companhias estão próximas de violar os covenants financeiros apresentam maior nível de gerenciamento de resultados (Iatridis \& Kadorinis, 2009; Silva, 2008; Franz et al., 2014; Duarte \& Galdi, 2018).

A variável Alavancagem é calculada por meio da divisão do passivo oneroso pelo patrimônio líquido da empresa. Espera-se que as empresas com maiores níveis de alavancagem possuem covenants financeiros mais restritivos e apresentem maior probabilidade de violar os covenants financeiros (Freudenberg et al., 2011; Bakar et al., 2012; Dahrawy et al., 2015; Palhares et al., 2019).

A variável Crescimento é calculada pela variação da receita líquida. Espera-se que as companhias em crescimento apresentem covenants financeiros mais restritivos (Freudenberg et al., 2011; Bakar et al., 2012). Já a variável rentabilidade é calculada por meio da divisão do EBITDA pelo valor médio do ativo total. Espera-se que a rentabilidade influencie negativamente na quantidade e no nível de restrição do covenant financeiro (Shi \& Sun, 2015; Emira \& Amel, 2015). Todas as variáveis de controle seguem descritas e apresentadas na Tabela 3. 
Tabela 3. Variáveis utilizadas no modelo

\begin{tabular}{|c|c|c|c|}
\hline Variável & Sinal & Definição & Fonte dos dados \\
\hline \multicolumn{4}{|l|}{ Explicada } \\
\hline Violação & & $\begin{array}{l}\text { Dummy de violação, sendo } 1 \text { se violou pelo menos } \\
\text { um covenant financeiro de contrato de dívida e } 0 \\
\text { caso contrário. }\end{array}$ & Notas explicativas \\
\hline \multicolumn{4}{|l|}{ Explicativa } \\
\hline $\begin{array}{l}\text { Níveis diferenciados de } \\
\text { governança corporativa }\end{array}$ & $(-)$ & $\begin{array}{l}\text { Dummy de governança corporativa, sendo } 1 \text { se } \\
\text { listadas nos níveis diferenciados da } \mathrm{B}^{3} \text { e } 0 \text { caso } \\
\text { contrário. }\end{array}$ & $\mathrm{B}^{3}$ \\
\hline \multicolumn{4}{|l|}{ Controle } \\
\hline Tamanho & $(-)$ & Logaritmo natural do ativo total & Economatica \\
\hline Gerenciamento de resultados & $(-)$ & $\begin{array}{l}\text { Nível de accruals discricionários mensurado pelo } \\
\text { modelo de Dechow et al. (1995) }\end{array}$ & Economatica \\
\hline Alavancagem & $(+)$ & $\begin{array}{c}\text { Divisão do passivo oneroso pelo patrimônio } \\
\text { líquido }\end{array}$ & Economatica \\
\hline Crescimento & $(+)$ & Evolução do ativo total. & Economatica \\
\hline Rentabilidade & $(-)$ & $\begin{array}{l}\text { Divisão do EBITDA pelo valor médio do ativo } \\
\text { total }\end{array}$ & Economatica \\
\hline
\end{tabular}

Fonte: elaborada pelos autores

\section{ANÁLISE DOS RESULTADOS}

\subsection{Estatística descritiva}

A Tabela 4 apresenta a estatística descritiva das variáveis utilizadas no modelo logístico. É possível verificar pela estatística descritiva que a média de violação ficou em 0,1496 , ou seja, aproximadamente $15 \%$ das observações da amostra violaram algum covenant financeiro no período de 2010 a 2018 . Já a variável explicativa níveis diferenciados de governança corporativa ficou com média 0,5229 , o que indica que 52\% da amostra é composta por empresas listadas no Nível 1, Nível 2 ou Novo Mercado de governança corporativa da B³

As companhias que compõem amostra apresentaram em média 15,41 do logaritmo do ativo total, -0,0009 de média de accruals discricionários, comprometeram em média 1,2 vezes do patrimônio líquido com passivo oneroso, reduziram suas vendas em média de 6,86\% e apresentaram rentabilidade média de $12 \%$ ao ano. Tais valores estão condizentes com resultados apresentados em outros artigos que utilizam dados de empresas brasileiras no período analisado.

Tabela 4. Estatística descritiva

\begin{tabular}{lcccc}
\hline \multicolumn{1}{c}{ Variáveis } & Média & Desvio Padrão & Mínimo & Máximo \\
\hline Violação & 0,1496 & 0,3568 & 0 & 1 \\
Níveis diferenciados de governança corporativa & 0,5229 & 0,4997 & 0 & 1 \\
Tamanho & 15,4173 & 1,3479 & 12,1141 & 19,1846 \\
Gerenciamento de resultados & $-0,0009$ & 0,0933 & $-0,2633$ & 0,3366 \\
Alavancagem & 1,2152 & 1,7589 & 0,0698 & 13,0236 \\
Crescimento & $-0,0686$ & 0,1367 & $-0,5847$ & 0,2296 \\
Rentabilidade & 0,1190 & 0,0960 & $-0,1331$ & 0,4578 \\
\hline
\end{tabular}

Fonte: elaborada pelos autores 


\subsection{Teste T Student}

A Tabela 5 apresenta o resultado do teste de média paramétrico T Student. Inicialmente foi identificado por intermédio de um teste $\mathrm{F}$ de igualdade de variâncias que os grupos de empresas listadas e não listadas em níveis diferenciados da $\mathrm{B}^{3}$ possuem variâncias diferentes. Efetuando-se o teste $\mathrm{t}$ de diferença de médias com grupos com variâncias distintas, verificou-se que existe diferença significativa entre as médias de empresas não listadas e listadas nos níveis diferenciados da $\mathrm{B}^{3}$ de 0,0290 . Tal resultado apresenta evidências iniciais de que as companhias não listadas nos níveis diferenciados de governança corporativa da $\mathrm{B}^{3}$ em média violam por mais vezes covenants financeiros do que as companhias listadas nos níveis diferenciados.

Tabela 5. Teste T Student

\begin{tabular}{lccc}
\hline \multicolumn{4}{c}{ Violação dos covenants financeiros } \\
\hline \multicolumn{1}{c}{ Grupos } & N & Média & Desvio padrão \\
\hline Não listadas nos níveis diferenciados & 625 & 0,1648 & 0,3713 \\
Listadas nos níveis diferenciados & 685 & 0,1358 & 0,3428 \\
\hline \multicolumn{1}{c}{ Diferença } & & $\mathbf{0 , 0 2 9 0 *}$ \\
\hline
\end{tabular}

Fonte: elaborada pelos autores

Nota: $* 10 \%, * * 5 \%$ e *** $1 \%$ de significância.

Embora esse resultado suporte a hipótese 1 desta pesquisa, ele fica limitado à comparação das médias, não levando-se em conta a heterogeneidade existente entre as empresas dos próprios grupos considerados. Na próxima subseção apresentam-se os resultados do modelo logístico exposto conforme equação 1 , o qual permite que tais diferenças sejam levadas em consideração.

\subsection{Análise de regressão}

A Tabela 6 apresenta os resultados do modelo logístico da pesquisa, tal como exposto na equação 1. Observa-se inicialmente que o modelo da pesquisa apresenta boa qualidade de estimação da probabilidade de violação de covenants financeiros, na medida em que não se rejeita a hipótese de qualidade de ajuste do teste de Hosmer-Lemeshow (prob > chi2 =0,5586), que a área abaixo da curva ROC é igual a 0,73 e que $86 \%$ das observações foram classificadas de modo correto.

Os resultados presentes na Tabela 6 consideram todas as 1.310 observações da amostra e apontam que a hipótese da pesquisa não pode ser rejeitada a um nível de confiança de $95 \%$. Ao se verificar sinal negativo e significativo para o coeficiente do $\beta_{l}$, evidencia-se que empresas listadas no Nível 1, Nível 2 ou Novo Mercado apresentam menor probabilidade de violar os covenants financeiros estabelecidos nos contratos de dívida em comparação com as companhias não listadas nos respectivos níveis. Tal resultado corrobora com a evidência inicial apontada pelo teste T Student e suporta a hipótese da pesquisa de que companhias brasileiras listadas nos níveis diferenciados de governança corporativa da $\mathrm{B}^{3}$ apresentam menor probabilidade de violarem os covenants financeiros estabelecidos nos contratos de dívida.

Tais resultados estão em linha com a literatura internacional e nacional, os quais apontam que empresas com maiores níveis de governança corporativa apresentam menor quantidade e folga nos limites dos covenants financeiros de contratos de dívida (Li et al., 2011; Bakar et al., 2012; Xi et al., 2014; Dahrawy et al., 2015; Konraht \& Vicente, 2019; Palhares et al., 2019). 
Tabela 6. Resultados da regressão logística

\begin{tabular}{|c|c|c|}
\hline Violação $_{\text {it }}$ & Coeficiente & p-Valor \\
\hline Níveis diferenciados de governança corporativa & $-0,4364$ & $0,014 * *$ \\
\hline Tamanho & $-0,0098$ & 0,882 \\
\hline Gerenciamento de resultados & $-2,5892$ & $0,009 * * *$ \\
\hline Alavancagem & 0,1902 & $0,000 * * *$ \\
\hline Crescimento & 0,8970 & 0,249 \\
\hline Rentabilidade & $-7,6638$ & $0,000 * * *$ \\
\hline Constante & $-0,8092$ & 0,431 \\
\hline Efeito Fixo de Ano & \multicolumn{2}{|c|}{ Sim } \\
\hline Observações & \multicolumn{2}{|c|}{1.310} \\
\hline $\mathrm{R}^{2}$ & \multicolumn{2}{|c|}{0,1211} \\
\hline Teste de White & \multicolumn{2}{|c|}{ Prob $>$ chi $2=0,5586$} \\
\hline Curva ROC & \multicolumn{2}{|c|}{0,7306} \\
\hline Tabela de classificação & \multicolumn{2}{|c|}{$86,03 \%$} \\
\hline
\end{tabular}

Fonte: elaborada pelos autores

Nota: * $10 \%, * * 5 \%$ e *** $1 \%$ de significância.

A Tabela 7 apresenta os resultados do evento ocorrer, demonstrando por meio dos odds ratio que a chance de uma empresa listada no Nível 1, Nível 2 ou Novo Mercado de governança corporativa da B ${ }^{3}$ violar um covenant financeiro é 35,36\% menor do que uma empresa não listada em tais níveis. Já analisando os resultados do efeito marginal, demonstra probabilidade de $12,70 \%$ para uma empresa violar um covenant, porém, se a empresa estiver listada nos níveis diferenciados de governança corporativa da $\mathrm{B}^{3}$ sua probabilidade de violar caí em média 0,0488 pontos percentuais.

Tabela 7. Chances de violar um covenant financeiro

\begin{tabular}{|c|c|c|c|c|}
\hline Variáveis & Odds Ratio & p-Valor & Efeito Marginal & p-Valor \\
\hline Níveis diferenciados de governança corporativa & 0,6464 & $0,014 * *$ & $-0,0489$ & $0,030 * *$ \\
\hline Tamanho & 0,9903 & 0,882 & $-0,0011$ & 0,887 \\
\hline Gerenciamento de resultados & 0,0751 & $0,009 * * *$ & $-0,2870$ & 0,574 \\
\hline Alavancagem & 1,2095 & $0,000 * * *$ & 0,0211 & 0,562 \\
\hline Crescimento & 2,4521 & 0,249 & $-0,0994$ & 0,572 \\
\hline Rentabilidade & 0,0005 & $0,000 * * *$ & $-0,8495$ & 0,562 \\
\hline Probabilidade de violação do covenant & & & \multicolumn{2}{|c|}{$\mathbf{0 , 1 2 7 0}$} \\
\hline
\end{tabular}

Fonte: elaborada pelos autores

Nota: $* 10 \%, * * 5 \%$ e *** $1 \%$ de significância.

Por meio dos resultados das variáveis de controle, identificamos que as empresas com maior nível de gerenciamento de resultados apresentam menor probabilidade de violar os covenants financeiros, consistente com as evidências presentes em Iatridis e Kadorinis (2009), Silva (2008), Franz et al. (2014) e Duarte \& Galdi (2018).

Tal resultado sugere que gestores possuem incentivos à efetuarem estratégias contábeis discricionárias quando estão próximos de violar os covenants financeiros e acrescentam ainda mais importância ao papel desempenhado pela governança corporativa de disciplinar ações discricionárias dos gestores com vistas à gestão dos indicadores inerentes às cláusulas restritivas. Consistente com tal ponto, verifica-se ainda que o nível de rentabilidade minimiza a probabilidade de violar os covenants financeiros (Shi \& Sun, 2015; Emira \& Amel, 2015).

Já as empresas com maior alavancagem e em crescimento apresentam maior probabilidade de violarem os covenants financeiros, resultados em linha com os achados de Freudenberg et al. (2011), Bakar et al. (2012) e Palhares et al. (2019), os quais evidenciaram que as empresas alavancadas e em crescimento apresentam maior quantidade de covenants financeiros e restrição elevada nos respectivos limites. 
De forma geral, os resultados deste estudo seguem alinhados ao papel da governança corporativa de disciplinar ações dos gestores e mitigar problemas de agência. As contribuições deste estudo se estendem em uma perspectiva prática na medida que suportam e justificam a inclusão de cláusulas financeiras mais restritas em contratos de dívidas de empresas não listadas nos níveis diferenciados de governança corporativa da $\mathrm{B}^{3}$. $\mathrm{Na}$ prática, tais níveis podem ser utilizados como subsídio adicional por credores na avaliação dos riscos contratuais e como fator que suporta e justifica a necessidade de inclusão de covenants financeiros nos contratos de dívida (Beiruth et al., 2017).

Especificamente, em uma perspectiva acadêmica, os resultados suportam a utilização dos níveis diferenciados de governança corporativa da $\mathrm{B}^{3}$ como proxy para governança na medida em que sugerem que empresas listadas nos níveis diferenciadas da $\mathrm{B}^{3}$ (Nível 1, Nível 2 e Novo Mercado) possuem menor probabilidade de violação dos covenants financeiros. Tal ponto amplia os resultados constantes em Palhares et al. (2019), nos quais o tamanho do conselho de administração e a concentração de propriedade são fatores que influenciam na quantidade de covenants a serem inseridos durante o processo de confecção dos contratos de dívida.

Tais mecanismos de monitoramento, ao se relacionarem diretamente com as regras implementadas pela $\mathrm{B}^{3}$ referentes aos requisitos mínimos de entrada nos diferentes níveis de governança, evidenciam não só que a utilização dos níveis diferenciados de governança da $\mathrm{B}^{3}$ podem ser usados como proxy para governança corporativa em contextos de contratos de dívida, mas que a estrutura de governança dos níveis diferenciados da $\mathrm{B}^{3}$ é complementar aos covenants financeiros para além do processo de formação desses contratos. Isso porque os resultados indicam que tal estrutura auxilia na própria limitação de ações discricionárias dos gestores no que tange ao gerenciamento de índices contábeis em momentos ex-post à confecção dos contratos com vistas à não violação dessas cláusulas financeiras restritivas.

\section{CONCLUSÃO}

A pesquisa teve como objetivo analisar se as companhias brasileiras de capital aberto listadas nos níveis diferenciados de governança corporativa apresentam menor probabilidade de violar os covenants financeiros estabelecidos nos contratos de dívidas. Os resultados da presente pesquisa evidenciam que as companhias listadas nos níveis diferenciados de governança corporativa da $\mathrm{B}^{3}$ apresentam menor probabilidade de violar os covenants financeiros estabelecidos nos contratos de dívidas do que as companhias não listadas nos respectivos níveis.

Tal resultado segue em linha com os achados da literatura internacional e nacional ao investigar a influência da adoção das boas práticas de governança corporativa na limitação de ações discricionárias dos gestores e na mitigação de conflitos de agência.

Especificamente, os resultados suportam a utilização dos níveis diferenciados de governança corporativa da $\mathrm{B}^{3}$ como proxy para governança corporativa em contextos em que existem conflitos de interesses entre as partes envolvidas, como é o caso de contratos de dívidas. Tal ponto indica que a estrutura de governança não só é complementar aos covenants financeiros durante processo de formação dos contratos e de mitigação dos conflitos de agência, mas também auxilia na própria limitação das ações discricionárias dos gestores no que tange ao gerenciamento de índices contábeis em momentos ex-post à confecção dos contratos com vistas à não violação de cláusulas financeiras restritivas.

Durante desenvolvimento da base de dados de covenants foi identificado que algumas companhias que apresentaram dívidas bancárias no balanço patrimonial não informaram se tinham ou não covenants financeiros, conforme CPC 26 (R1). Tal ponto, embora se configure em partes como limitação do alcance da base de dados da pesquisa, indica também um alerta para que as discussões acerca do detalhamento dos covenants estipulem mecanismos que permitam aos stakeholders terem maiores acessos não só às condições de violação, mas também às características constantes nas próprias cláusulas dos contratos de dívida. Para desenvolvimento de novas pesquisas, sugere-se analisar quais tipos de ações discricionárias específicas são limitadas pelo aumento do nível de governança em conformidade com os requisitos de cada nível da $\mathrm{B}^{3}$.

\section{REFERÊNCIAS}

Almeida, J. C. G., Scalzer, R. S., \& Costa, F. M. (2008). Níveis diferenciados de governança corporativa e grau de conservadorismo: estudo empírico em companhias abertas listadas na Bovespa. Revista de Contabilidade e Organizações, 2(2), 118-131. DOI: https://doi.org/10.11606/rco.v2i2.34709 
Baioco, V., \& Almeida, J. (2017). Efeitos do comitê de auditoria e do conselho fiscal na qualidade da informação contábil no Brasil. Revista Contabilidade \& Finanças, 28(4), 229-248. DOI: https://doi.org/10.1590/1808$057 \times 201703250$

Bakar, I. S. A., Mather, P., \& Tanewski, G. (2012). Corporate Govenance and Covenant Restrictiveness in Private Debt Contracts. Working paper. DOI: http://dx.doi.org/10.2139/ssrn.2166616

Beiruth, A. X., Fávero, L. P. L., Murcia, F. D. R., Almeida, J. E. F., \& Brugni, T. (2017). Structural changes in covenants through the adoption of IFRS in Brazil. Accounting Forum, 41, 147-160. DOI: http://dx.doi. org/10.1016/j.accfor.2017.06.004

Beneish, D. M., \& Press, E. (1993). Costs of Technical Violation of Accounting-Based Debt-Covenants. The Accounting Review, 68(2), 233-257.

Brasil, Bolsa e Balcão - B33. (2020). Segmentos de listagem. Recuperado de: <http://www.b3.com.br/pt_br/ produtos-e-servicos/solucoes-para-emissores/segmentos-de-listagem/sobre-segmentos-de-listagem/>

Borges, L. F. X. (1999). Covenants: Instrumentos de Garantia em Project Finance. Revista do BNDES, 5(9), $105-$ 121.

Bússsola do Investidor. (2020). Níveis de Governança Corporativa na Bovespa. Recuperado de: https://www. bussoladoinvestidor.com.br/niveis-governanca-corporativa-bovespa/

Caixe, D. F., \& Krauter, E. (2014). Relação entre Governança corporativa e valor de mercado: mitigando problemas de endogeneidade. Brazilian Business Review, 11(1), 96-107. DOI: http://dx.doi.org/10.15728/ bbr.2014.11.1.5

Christensen, H. B., \& Nikolaev, V. V. (2012). Capital versus performance covenants in debt contracts. Journal of Accounting Research, 50(1), 75-116. DOI: https://doi.org/10.1111/j.1475-679X.2011.00432.X

Chava, S., Fang, S., Kumar., \& Prabhat, S. (2019). Debt Covenants and Corporate Govenance. Annual Review of Financial Economics, 11, 197-219. DOI: https://doi.org/10.1146/annurev-financial-110716-032511

Clemente, A., Antonelli, R. A., Scherer, L. M., \& Mussi, S. C. A. P. (2014). O mercado brasileiro precifica a adesão e a migração aos níveis diferenciados de governança corporative? Revista de Administração e Contabilidade da Unisinos, 11(2), 140-152. DOI: https://doi.org/10.4013/base.2014.112.04

Comitê de Pronunciamentos Contábeis - CPC 26 (R1). (2011). Dispõe sobre Apresentação das Demonstrações Contábeis. Brasília. 2011. Recuperado em 09 de julho, 2019, de http://static.cpc.aatb.com.br/Documentos/312 CPC_26_R1_rev\%2013.pdf

Costa, C. M., Matte, A. M., \& Mont-Mor, D. S. (2018). Endividamento e decisões contábeis: a relação não linear entre dívida e qualidade dos lucros. Revista de Contabilidade e Organizações, 12:e137077. DOI: http:// dx.doi.org/10.11606/issn.1982-6486.rco.2018.137077.

Costello, A. M., \& Moerman, R. W. (2011). The Impact of Financial Reporting Quality on Debt Contracting: Evidence from Internal Control Weakness Reports. Journal of Accounting Research, 49(1), 97-136. DOI: https://doi.org/10.1111/j.1475-679X.2010.00388.x

Dahrawy, K. D. M., Ghany, M. M. A., \& Mohamed, O. M. F. (2015). The effect of accounting information and corporate governance mechanisms on debt covenants- an applied study on firms listed in the egyptian stock Market. Working Paper. Global Conference on Business and Finance Proceeding, 10(1), 59-68.

Dalmácio, F. Z., Lopes, A. B., Sarlo Neto, A., \& Rezende, A. J. (2011). A influência da adoção de práticas diferenciadas de governança corporativa sobre a acurácia das previsões dos analistas do mercado brasileiro. V Congresso ANPCONT, 1, 1-17.

Dawson, G., Denford, J., Williams, C. K., Preston, D., \& Desouza, K. C. (2016). An Examination of Effective IT Governance in the Public Sector Using the Legal View of Agency Theory. Journal of Management Information Systems, 33(4), 1180-1208. DOI: https://doi.org/10.1080/07421222.2016.1267533

Dechow, P. M., Sloan, R. G., \& Sweeney, A. P. (1995). Detecting earnings management. The Accounting Review, 70(2), 193-225

Demerjian, P. R. (2017). Uncertainty and debt covenants. Review of Accounting Studies, 22(3), 1156-1197. DOI: https://doi.org/10.1007/s1114 
Demiroglu, C., \& James, C. M. (2010). The Information Contento fBank Loan Covenants. The Review of Financial Studies, 23(10), 3700-3737. DOI: https://doi.org/10.1093/rfs/hhq054

Denis, D. K., \& McConnell, J. J. (2003). International Corporate Governance. The Journal of Financial and Quantitative Analysis, 38(1), 1-36. DOI: https://doi.org/10.2307/4126762

Duarte, E. R., \& Galdi, F. C. (2018). Gerenciamento de Resultados e Ruptura dos Covenants: um estudo empírico no Brasil. XXI Seminário em Administração, São Paulo, SP, Brasil.

Emira, H., \& Amel, B. (2015). The Determinants of Bond Covenants: The Case of US Firms. Euro-Asian Journal of Economics and Finance, 3(3), 139-157.

Franz, D., Hassabelanby, R., \& Lobo, G. J. (2014). Impact of proximity to debt covenant violation on earnings management. Review Accounting Studies, 19, 473-505. DOI: https://doi.org/10.1007/s11142-013-9252-9

Freudenberg, F., Imbierowicz, B., Saunders, A., \& Steffen, S. (2011). Covenant Violations, Loan Contracting, and Default Risk of Bank Borrowers. Working paper. NYU Working Paper No. 2451/31417. Recuperado de https://ssrn.com/abstract=2284660

Funchal, B., \& Mont-Mor, D. S. (2016). Corporate Governance and Credit Access in Brazil: The Sarbanes-Oxley Act as a Natural Experiment. Corporate Governance: An International Review, 24(5), 528-547. DOI: https:// doi.org/10.1111/corg.12151

Gondrige, E. O., Clemente, A., \& Espej, M. M. S. B. (2012). Estrutura do conselho de administração e valor das companhias brasileiras. Brazilian Business Review, 9(3), 71-93. DOI: http://dx.doi.org/10.15728/ bbr.2012.9.3.4

González, J. S., \& García-Meca, E. (2014). Does Corporate Governance Influence Earnings Management in Latin American Markets? Journal of Business Ethics, 121(3), 419-440. DOI: https://10.1007/s10551-103-1700-8

Iatridis, G., \& Kadorinis, G. (2009). Earnings management and firm financial motives: A financial investigation of UK listed firms. International Review of Financial Analysis, 18, 164-173. DOI: https://doi.org/10.1016/j. irfa.2009.06.001

Inamura, Y. (2009). The determinants of accounting based covenants in public debt contracts. Journal of International Business Research, 8, 1-15.

Ismail, R. H. (2014). The Determinants of Financial Covenants on Private Debt: The Case of Listed French Companies. Research Journal of Finance and Accounting, 5(15), 176-184.

Klock, M. S., Mansi, S. A., \& Maxwell, W. F. (2005). Does Corporate Governance Matter do Bondholders?. The Journal of Financial and Quantitative Analysis, 40(4), 693-719. DOI: https://doi.org/10.1017/ S0022109000001940

Konraht, J. M., \& Vicente, E. F. R. (2019). Determinantes da utilização de covenants contábeis nas debêntures emitidas pelas empresas listadas na Bolsa Brasil Balcão. Advances in Scientific and Applied Accounting, 12(1), 101-119. DOI: https://dx.doi.org/10.14392/asaa.2019120106

Li, S., Qiu, J., \& Wan, C. (2011). Corporate Globalization and bank lending. Journal of International Business Research, 42(8), 1016-1042. DOI: https://doi.org/10.1057/jibs.2011.29

Machado, M. R. R., \& Gartner, I. V. (2018). The Cressey hypothesis (1953) and an investigation into the occurrence of corporate fraud: an empirical analysis conducted in Brazilian banking institutions. Revista Contabilidade \& Finanças, 29(76), 60-81. DOI: https://doi.org/10.1590/1808-057x201803270

Mapurunga, P. V. R., Ponte, V. M. R., \& Oliveira, M. C. (2015). Determinantes das práticas de governança corporativa: Um estudo nas empresas registradas na CVM. Advances in Scientific and Applied Accounting, 8(3), 374-395. DOI: http://dx.doi.org/10.14392/asaa.2015080306

Maranho, F. S., \& Leal, R. (2018). Corporate governance and firm performance in Latin America: a meta-analysis. Revista Latinoamericana de Administracion, 31(1), 195-211. DOI: https://doi.org/10.1108/ARLA-04-20170126

Minadeo, R. (2018). Corporate governance: concepts, situational analysis and reflections on the situations based on theoretical framework of L'Huillier (2014) and Martin, Santos, Dias Filho (2004). Brazilian Journal of Development, 4(3), 995-1019. 
Miglani, S., Ahmed, K., \& Henry, D. (2015). Voluntary corporate governance structure and financial distress: evidence from Australia. Journal of Contemporary Accounting \& Economics, 11(1), 18-30. DOI: https://doi. org/10.1016/j.jcae.2014.12.005

Moir, L., \& Sudarsanam, S. (2007). Determinants of financial covenants and pricing of debt in pri $\neg$ vate debt contracts: the UK evidence. Accounting and Business Research, 37(2), 151-166. DOI: https://doi.org/10.108 0/00014788.2007.9730066

Nardi, P. C. C., \& Nakao, S. H. (2008). Impacto da Entrada nos Níveis Diferenciados de Governança Corporativa sobre a Imagem Institucional das Empresas. Revista Contabilidade Vista \& Revista, 19(2), 85-111.

Nini, G., Smith, D. C., \& Sufi, A. (2009). Creditor control rights and firm investment policy. Journal of Financial Economics, 92(3), 400-420. DOI: https://doi.org/10.1016/j.jfineco.2008.04.008

Nisiyama, E. K., \& Nakamura, W. T. (2018). Diversity of the board and capital structure. Journal of Business Management. 58(6), 551-563. DOI: http://dx.doi.org/10.1590/S0034-759020180604

Nikolaev, V.V. (2010). Debt Covenants and Accounting Conservatism. Journal of Accounting Research, 48(1), 137-175. DOI: https://doi.org/10.1111/j.1475-679X.2009.00359.x

Palhares, C. M. G., Carmo, C. H. S., Ferreira, M. P., \& Ribeiro, A. M. (2019). Efeitos da concentração de propriedade e da estrutura do conselho de administração nos covenants de debêntures emitidas pelas empresas brasileiras de capital aberto. Revista de Contabilidade e Organizações, 13:e158820. DOI: http://dx.doi.org/10.11606/ issn.1982-6486.rco.2019.158820

Press, E., \& Weintrop, J. (1991). Financial Statement Disclosure of Accounting-Based Debt Covenants. Accounting Horizons. 5(1), 64-74.

Prilmeier, R. (2017). Why do loans contain covenants? Evidence from lending relationships. Journal of Financial Economics, 123(3), 558-579. DOI: https://doi.org/10.1016/j.jfineco.2016.12.007

Robicheaux, S. H., Fun, X., \& Ligon, J. A. (2007). Convertible Debt Use and Corporate Governance. Quarterly Journal of Business and Economics, 46(3), 65-94.

Rossoni, L., \& Silva, G. L. M. (2013). Legitimidade, Governança Corporativa e Desempenho: Análise das empresas da BM\&FBOVESPA. Revista de Administração de Empresas, 53(3), 272-289. DOI: http://dx.doi. org/10.1590/S0034-75902013000300005

Silva, A. H. C. (2008). Escolha de práticas contábeis no Brasil: uma análise sob a ótica da hipótese dos covenants contratuais. Tese (Doutorado em Ciências Contábeis) - Programa de Pós Graduação em Ciências Contábeis, Universidade de São Paulo, São Paulo. Recuperado e 20 abril, 2019, de http://www.teses.usp.br/teses/ disponiveis/12/12136/tde-16012009-120147/pt-br.php

Silva, E. S., Kayo, E. K., \& Nardi, R. Y. S. (2016). Governança corporativa e criação de valor em aquisições. Revista de Gestão, 23. 222-232. DOI: http://dx.doi.org/10.1016/j.rege.2016.06.004

Silva, E. S., Santos, J. F., \& Almeida, M. A. (2011). Conselho de Administração: uma análise da influência nos níveis de endividamento. Revista Brasileira de Gestão de Negócios, 13(41), 440-453.

Shi, G., \& Sun, J. (2015). Corporate Bond Covenants And Social Responsibility Investiment. Journal of Business Ethics, 131(2), 285-303. DOI: https://doi.org/10.1007/s10551-014-2272-y

Shleifer, A., \& Vishny, R. (1997). A survey of corporate gorvenance. Journal of Finance, 52, 737-775.

Sonza, I., \& Kloeckner, G. (2014). Governança Corporativa Influência a Eficiência das Empresas Brasileiras? Revista Contabilidade \& Finanças, 25(65), 145-160. DOI: https://doi.org/10.1590/S1519-70772014000200005

Ulum, Z. K. A. B., Wafa, S. A. W. S. K., Karim, M. R. A., \& Jamal, A. A. A. (2014). Corporate Governance Practices of Insurance Companies: Attributes and Accountability. Journal of Corporate Governance, 13(1), 47-57.

Xi, L., Tuna, I., \& Vasvari, F. P. (2014). Corporate Governance and covenants in debt contracts. Working Paper presented at The American Accounting Association Conference, San Francisco. DOI: http://dx.doi. org/10.2139/ssrn. 1988272

\section{Como citar este artigo}

Oliveira, W. da C. de; \& Monte-Mor, D. S. (2020). Níveis diferenciados de governança corporativa e a probabilidade de violação dos covenants financeiros. Revista de Contabilidade e Organizações, 14:e168945. DOI: http://dx.doi.org/10.11606/issn.1982-6486.rco.2020.168945 
Apêndice A - Pontos analisados durante coleta dos dados da variável dependente

\begin{tabular}{|c|c|c|c|c|c|c|c|c|c|c|}
\hline \multirow{2}{*}{ Pontos } & \multicolumn{10}{|c|}{ Número de observações } \\
\hline & 2010 & 2011 & 2012 & 2013 & 2014 & 2015 & 2016 & 2017 & 2018 & Tota \\
\hline Divulgou se tinha ou não covenants nas notas explicativas & 157 & 172 & 187 & 193 & 204 & 210 & 216 & 220 & 220 & 1.779 \\
\hline Não divulgou se tinha ou não covenants nas notas explicativas & 86 & 73 & 64 & 65 & 59 & 64 & 63 & 58 & 69 & 601 \\
\hline Não localizadas as notas explicativas & 23 & 28 & 25 & 24 & 28 & 20 & 22 & 26 & 15 & 211 \\
\hline Total de observações & 266 & 273 & 276 & 282 & 291 & 294 & 301 & 304 & 304 & 2.591 \\
\hline Tinha covenant nas notas explicativas & 143 & 154 & 167 & 171 & 180 & 186 & 191 & 197 & 200 & 1.589 \\
\hline Não tinha covenant nas notas explicativas & 14 & 18 & 20 & 22 & 24 & 24 & 25 & 23 & 20 & 190 \\
\hline Total de observações & 157 & 172 & 187 & 193 & 204 & 210 & 216 & 220 & 220 & 1.779 \\
\hline Tinha algum covenant financeiro nas notas explicativas & 135 & 145 & 157 & 161 & 169 & 170 & 177 & 183 & 186 & 1.483 \\
\hline Só tinha covenant não financeiro nas notas explicativas & 8 & 9 & 10 & 10 & 11 & 16 & 14 & 14 & 14 & 106 \\
\hline Total de observações & 143 & 154 & 167 & 171 & 180 & 186 & 191 & 197 & 200 & 1.589 \\
\hline Violou algum covenant financeiro & 15 & 19 & 25 & 24 & 31 & 40 & 32 & 34 & 31 & 251 \\
\hline Não violou nenhum covenant financeiro & 120 & 126 & 132 & 137 & 138 & 130 & 145 & 149 & 155 & 1.232 \\
\hline Total de observações & 135 & 145 & 157 & 161 & 169 & 170 & 177 & 183 & 186 & 1.483 \\
\hline
\end{tabular}

